\title{
Nasal Wash Specimen
}

National Cancer Institute

\section{Source}

National Cancer Institute. Nasal Wash Specimen. NCI Thesaurus. Code C155834.

A biospecimen collected from the nasal passages by washing. 